\title{
Glutathione S Transferases: Biochemistry, Polymorphism and Role in Colorectal Carcinogenesis
}

\author{
Saniya Nissar ${ }^{1,2,3}$, Aga Syed Sameer ${ }^{*}$, Roohi Rasool ${ }^{2}$, Nissar A Chowdri ${ }^{5}$ and Fouzia Rashid ${ }^{3}$ \\ ${ }^{1}$ Department of Biochemistry, University of Kashmir, India \\ ${ }^{2}$ Department of Immunology and Molecular Medicine, Sher-I-Kashmir Institute of Medical Sciences, India \\ ${ }^{3}$ Department of Clinical Biochemistry, University of Kashmir, India \\ ${ }^{4}$ Department of Basic Medical Sciences, College of Medicine, King Saud Bin Abdulaziz University for Health Sciences. Jeddah, KSA \\ ${ }^{5}$ Department of General Surgery, Sher-I-Kashmir Institute of Medical Sciences, India
}

*Corresponding author: Aga Syed Sameer, Department of Basic Medical Sciences, College of Medicine, King Saud Bin Abdulaziz University for Health Sciences. Jeddah, KSA, Tel: +966542035086; E-mail: agas@ksau-hs.edu.sa

Received date: February 19, 2017; Accepted date: March 10, 2017; Published date: March 15, 2017

Copyright: (c) 2017 Nissar S, et al. This is an open-access article distributed under the terms of the Creative Commons Attribution License, which permits unrestricted use, distribution, and reproduction in any medium, provided the original author and source are credited.

\begin{abstract}
Glutathione S-transferases (GSTs) are enzymes detoxifying a wide range of hazardous substances both of endogenous or exogenous origin, such as reactive oxygen species (ROS) or xenobiotics and environmental carcinogens; thereby imparting protection to DNA against oxidative damage. GST gene polymorphisms on the other hand, exert an effect on the functioning of enzymes encoded by these genes at both gene expression level and the activity of the protein. In this way it may influence the possibility of detoxification of carcinogens, and consequently, the level of DNA damage; thus it may have an effect on the risk of development of cancer. In this review we aim to understand the function of GSTs in the xenobiotic metabolism and their role in modulation of colorectal cancer (CRC).
\end{abstract}

Keywords: GST genes; Xenobiotic metabolism; Polymorphisms; CRC

\section{Introduction}

The Glutathione S-transferases (GSTs) are important Phase II biotransformation enzymes which play a key role in cellular detoxification, protecting macromolecules from attack by reactive electrophiles, environmental carcinogens, reactive oxygen species and chemotherapeutic agents [1]. GSTs are widely distributed in nature and are present in both prokaryotes and eukaryotes as the principal Phase II detoxifying enzymes [2]. They constitute a superfamily of ubiquitous, multifunctional enzymes (GSTs; EC 2.5.1.18) which catalyze the nucleophilic addition of the tripeptide glutathione (GSH; g-Glu-Cys-Gly) to several hazardous xenobiotics, including phase I electrophilic and carcinogenic metabolites [3-5] thereby, neutralizing their electrophilic sites and rendering the products more water-soluble and facilitating their elimination from the cell by Phase III enzymes [6]. In addition, GSTs can serve as peroxidases, isomerases and thiol transferases [7]. They also can play role in non-catalytic functions like modulation of signaling processes and non-substrate ligand binding [8].

Therefore, in this review, we aim to understand the role of GSTs in the metabolism of xenobiotics including carcinogens of both endo- as well as exogenous origin and the impact of GST gene polymorphisms in the human cancer susceptibility especially CRC.

\section{GST Genes and Its Types}

Human GSTs are divided into three main families: cytosolic, mitochondrial and membrane-bound microsomal. The cytosolic and mitochondrial GSTs are soluble enzymes with three-dimensional fold structural similarity. Almost all soluble GSTs are active as dimers of subunits of 23-30 kDa with subunits of 199-244 amino acids in length (identical, homodimers or different, heterodimers) subunits, and each dimer is encoded by independent genes [9]. Microsomal GSTs designated as 'membrane associated proteins in eicosanoid and glutathione metabolism' (MAPEGs) are structurally distinct from cytosolic GSTs but are functionally similar in the ability to catalyze the conjugation of GSH to electrophilic compounds [2]. Each class is coded by different genes located on different chromosome (Figure 1 and Table 1).

\begin{tabular}{|c|c|c|c|}
\hline S.no & Class & enzyme & $\begin{array}{l}\text { Chromosomal } \\
\text { location }\end{array}$ \\
\hline 1. & Cytosolic & $\begin{array}{l}\text { ALphA (a1,A2,A3,A4 } \\
\text { and a5) } \\
\text { mu (m1,M2,M3,M4 and } \\
\text { m5) } \\
\text { pi (p1) } \\
\text { sigma (s1) } \\
\text { theta (t1 and } t 2) \\
\text { zeta (z1) } \\
\text { omega (o1 and o2) }\end{array}$ & $\begin{array}{l}6 p 12 \\
1 p 13.3 \\
11 q 13.3 \\
4 q 21-22 \\
22 q 11.23 \\
14 q 24.3 \\
10 q 24.3\end{array}$ \\
\hline 2. & Mitochondrial & Kappa k1 & Not Determined \\
\hline 3. & mapeg & $\begin{array}{l}\text { gp I, MGST2 } \\
\text { gp I, FLAP } \\
\text { gp I, LTC4S } \\
\text { gp II, MGST3 } \\
\text { gp IV, MGST1 }\end{array}$ & $\begin{array}{l}4 q 28-31 \\
13 q 12 \\
5 q 35 \\
1 q 23 \\
22 p 13.1-13.2\end{array}$ \\
\hline
\end{tabular}




$$
\text { gp IV, PGES1 }
$$

$9 q 34.3$

Table 1: Genetic properties of human GSTS.

The cytosolic GSTs are the most complex family with seven sub divisions or classes designated as Alpha, Mu, Omega, Pi, Sigma, Theta and Zeta. Classification is based on amino-acid sequence similarities, physical structure of the genes (i.e., intron number and position) and immunological cross-reactivity [2]. There is greater than $60 \%$ identity within a class and relies mainly on the more highly conserved $\mathrm{N}$ terminal domain. The identity may reach $90 \%$ of sequence identity when this region comprises part of the active site, with residues that interact with GSH; however, a limit of $50 \%$ sequence identity has been set as a criterion for membership of a given class of mammalian GSTs [10].

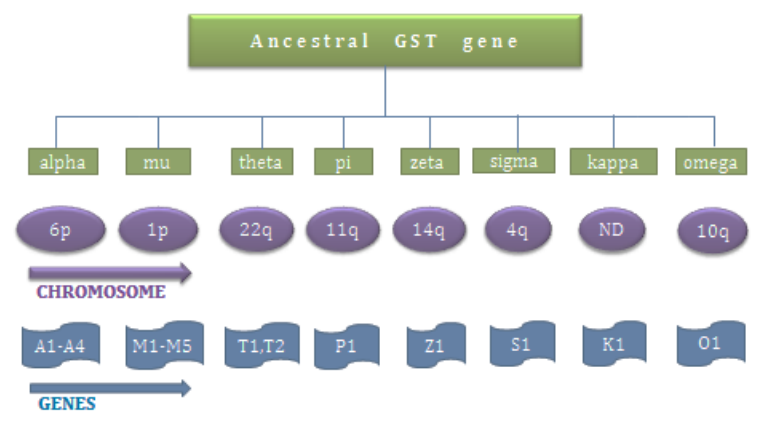

Figure 1: The glutathione-S-transferase supergene family.

\section{Metabolism of Xenobiotics by GSTs}

GSTs function widely in detoxifying electrophilic xenobiotics, such as chemical carcinogens, environmental pollutants, and antitumor agents but also play an important role in inactivation of secondary metabolites produced during oxidative stress like endogenous $\alpha, \beta$ unsaturated aldehydes, quinones, epoxides and hydroperoxides.

\section{Detoxification of exogeneous substrates}

GSTs are involved in mercapturic acid synthesis and catalyze the first of four steps of synthesis process. There is subsequent sequential removal of the $\gamma$-glutamyl moiety and glycine from the glutathione conjugate, followed by $\mathrm{N}$-acetylation of the resulting cysteine conjugate. GST enzymes form a part of an integrated defense strategy, and their usefulness depends on the combined activities, i.e. supply of GSH by glutamate cysteine ligase and glutathione synthase and alternatively acts on transporters to remove glutathione conjugates from the cell, which are eliminated then by the trans-membrane MRP (multidrug resistance-associated protein) from the cell [2]. There are nine MRP proteins belonging [11], to the $C$ family of $A B C$ transporters. MRP1 and MRP2 can disseminate glutathione conjugates and compounds complexed with GSH $[12,13]$. The RLIP76 (dinitrophenol-glutathione ATPase), a non-transmembrane protein upholds efflux of glutathione conjugate removal from cells [14].
GST isoenzymes have been shown to detoxify a large number of exogenous substrates including carcinogens, drugs and environmental pollutants. The cancer chemotherapeutic agents are also detoxified by GSTs like adriamycin, 1,3-bis (2-chloroethyl)-1-nitrosourea (BCNU), busulfan, carmustine, chlorambucil, cis-platin, crotonyloxymethyl-2cyclohexenone (COMC-6), melphalan, mitozantrone, and thiotepa, cyclophosphamide, ethacrynic acid [15]. Environmental chemicals and their metabolites detoxified by GST include acrolein, atrazine, DDT, inorganic arsenic, lindane, malathion, methyl parathion, muconaldehyde, and tridiphane [16,17]. A large number of epoxides, such as the antibiotic fosfomycin and those derived from environmental carcinogens, polycyclic aromatic hydrocarbons (PAHs) etc are detoxified by GST. Activated metabolite, N-acetoxy-PhIP of heterocyclic amine, 2-amino-1-methyl-6-phenylimidazo [4,5b]pyridine (PhIP), produced by cooking protein-rich food is also detoxified by cytosolic GST isoenzymes .

\section{Detoxification of endogenous products}

As a result of oxidative stress, the reactive oxygen species, the superoxide anion $\mathrm{O}^{-2}$, hydrogen peroxide $\mathrm{H}_{2} \mathrm{O}_{2}$, and the hydroxyl radical $\mathrm{HO}$ - inflict damage on DNA (direct/indirect) on membrane lipid, protein, and carbohydrate. Free radicals arising primarily through oxidative phosphorylation and other oxidase-catalyzed reactions are scavenged by the catalytic activities of superoxide dismutase, catalase and glutathione peroxidase and non-enzymatically by $a$-tocopherol, ascorbic acid, GSH, and bilirubin. Moreover the byproducts of oxidative stress are tackled by number of enzymes like Aldehyde dehydrogenase, alcohol dehydrogenase, aldo-keto reductase, GST, and Selenium-dependent glutathione peroxidase (GPx).

GST isoenzymes exhibit modest role in lipid peroxidation in membranes whereby hydroperoxides that breakdown to yield secondary electrophiles, including epoxyaldehydes, 2-alkenals, 4hydroxy-2-alkenals, and ketoaldehydes are produced. GSTs exhibit Seindependent glutathione peroxidase activity toward 1-palmitoyl-2-(13hydroperoxy-cis-9, trans-11-octadecadienoyl)-L-3-phosphatidylcholine and phosphatidylcholine hydroperoxide, reducing lipid hydroperoxides within membranes [18-20]. The transferases can also reduce cholesteryl hydroperoxides [21] and fatty acid hydroperoxides, including (S)-9-hydroperoxy-10,12-octadecadieonic acid and (S)-13hydroperoxy-9,11-octadecadieonic acid [20]. Among the end-products of lipid peroxidation, GSTs conjugate GSH with the 2 -alkenals acrolein and crotonaldehyde, as well as 4-hydroxy-2-alkenals of between 6 and 15 carbon atoms in length [22]. Further, GSTs catalyze the conjugation of cholesterol-5,6-oxide,epoxyeicosatrienoic acid, and 9,10epoxystearic acid with GSH indicating its role in cellular protection against a range of harmful electrophiles of oxidative stress [2].

Further it has been proposed that GST reactivates oxidized 1-cys peroxiredoxin (Prx) VI through glutathionylation followed by reduction of the mixed disulfide thereby combatting oxidative stress indirectly [23]. The Prx VI defends against cellular membrane damage by reducing phospholipid hydroperoxides to their respective alcohols. Also GSTs mediate the conjugation of harmful quinone-containing compounds with GSH preventing redox cycling reaction.

\section{Bioactivation of xenobiotics}

Conjugation of GSTs is supposed to form less reactive and readily excreted products. However, in some instances the glutathione conjugate is more reactive than the parent compound such as short- 
Page 3 of 9

chain alkyl halides that contain two functional groups and 1,2dihaloethanes, where the glutathione conjugate however, rearranges to form an episulfonium intermediate that is responsible for modifying DNA [24]. Also conjugation of GSH with the solvent dichloromethane results in the formation of the highly unstable Schloromethylglutathione, containing an electrophilic center capable of modifying DNA [24,25].

Allyl-, benzyl-, phenethyl-isothiocyanates, and sulforaphane, the moderately toxic compounds thatare reversibly conjugated by GST with GSH to yield thiocarbamates which spontaneously degrade to their isothiocyanates releasing GSH, followed by export from cells via MRP1 or MRP2. Thereafter, the isothiocyanate may be taken up again by the cell and re-conjugated with GSH, only to be re-exported as the thiocarbamate and revert to the isothiocyanate. This cyclical process results in depletion of intracellular GSH and assists distribution of isothiocynates throughout the body. Should isothiocyanates be taken up by cells that have a low GSH content, they may not be conjugated with GSH, but rather are more likely to thiocarbamylate proteins, a process that can result in cell death [26].

In the liver conjugation of haloalkenes with GSH, leads to the generation of reactive thioketenes, thionoacylhalides, thiiranes, and thiolactones through the actions of renal cysteine conjugate $\beta$-lyase in the kidneys [27]. Further the ability of GST to produce reactive metabolites has been exploited to target tumors that overexpress particular transferases in cancer chemotherapy [28]. For example the latent cytotoxic drug TER286 (now called TLK286) is activated by GST through a $\beta$-elimination reaction to yield an active analogue of cyclophosphamide [29]. More recently, the prodrug PABA/NO (O2[2,4-dinitro-5-(N-methyl-N-4-carboxyphenylamino)phenyl] 1-N,Ndimethylamino)diazen-1-ium-1,2-diolate) has been designed to generate cytolytic nitric oxide upon metabolism by GST [30].

\section{Role of GSTs in biochemical processes}

A large number of biochemical processes require the direct involvement of GST enzymes. These enzymes play a pivotal role in the biosynthesis of leukotrienes, prostaglandins, testosterone, and progesterone, as well as the degradation of tyrosine. The detailed role of each of the gene and its enzyme is provided in the Table 2.

\begin{tabular}{|c|c|c|c|}
\hline Gene & Enzyme & Major Substrates & Functions \\
\hline \multirow{4}{*}{ GSTA1 } & \multirow{3}{*}{ GSTA1-1 } & $\begin{array}{l}\text { 1-chloro-2,4-dinitrobenzene } \\
\text { (CDNB) }\end{array}$ & PGH2 $\rightarrow$ PGE2; \\
\hline & & $\begin{array}{l}\text {,7-chloro-4nitrobenzo-2- } \\
\text { oxa-1,3diazole; }\end{array}$ & $\mathrm{PGH} 2 \rightarrow \mathrm{PGF} 2 \alpha$ \\
\hline & & $\Delta 5$-androstene-3,17-dione & $\begin{array}{l}\text { Isomerization } \\
\text { androstene }\end{array}$ \\
\hline & & & $\mathrm{PGH} 2 \rightarrow \mathrm{PGD} 2$ \\
\hline \multirow[t]{2}{*}{ GSTA2 } & GSTA2-2 & $\begin{array}{l}\text { CDNB, } \\
\text { nitrobenzo-2-oxa-1,3 } \\
\text { diazole, } \\
\text { hydroperoxide }\end{array}$ & $\mathrm{PGH} 2 \rightarrow \mathrm{PGF} 2 \alpha$, \\
\hline & & & $\begin{array}{l}\text { reduction of cumene } \\
\text { hydroperoxide }\end{array}$ \\
\hline GSTS1 & GSTS1 & PGD2 synthase & $\mathrm{PGH} 2 \rightarrow \mathrm{PGD} 2$ \\
\hline
\end{tabular}

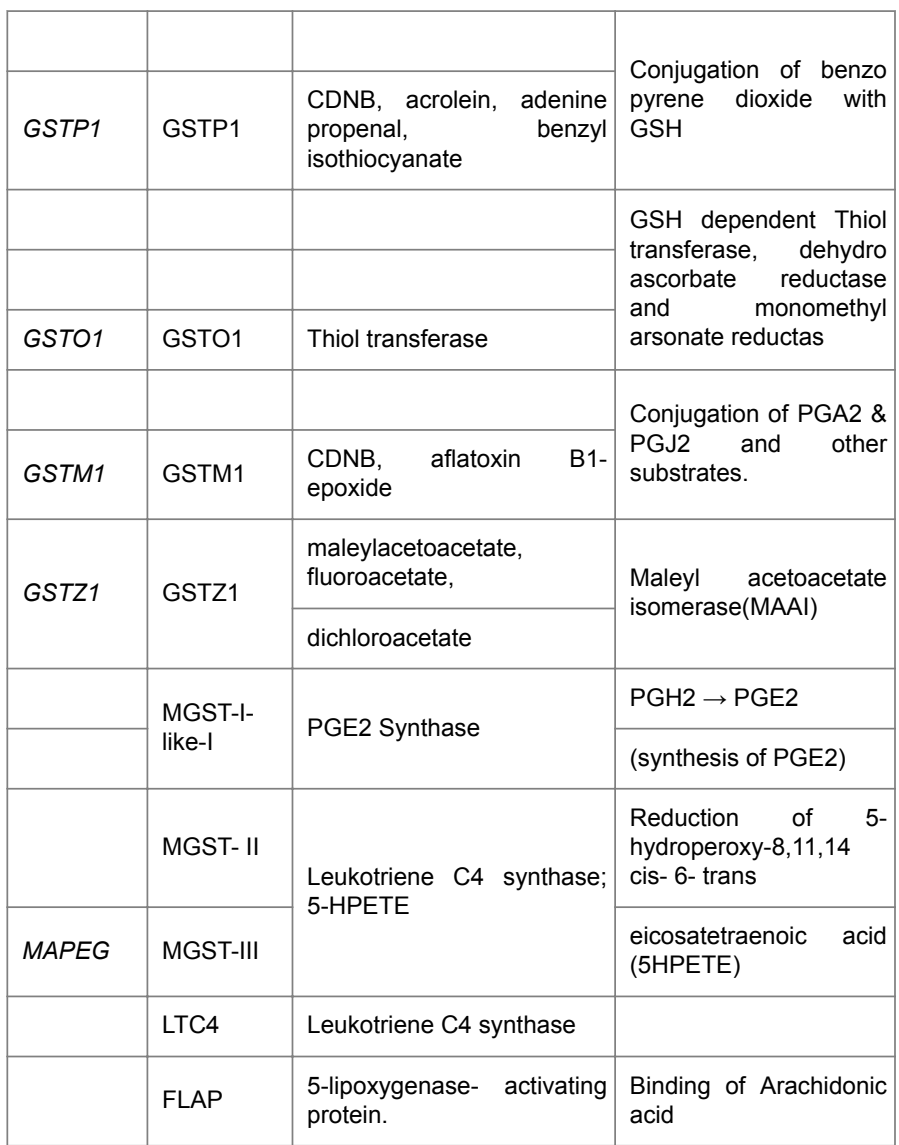

Table 2: Biochemical properties of human GSTs.

\section{Role of GSTs in Regulation of Cellular Signaling Via Kinases}

Decreased detoxification of possible carcinogens due to the absence or decreased expression of GSTP may result in the malignant transformation and disease progression. In addition, its increased expression is highly correlated with multidrug resistance due to weak affinity of GST-mediated conjugation of GSH for the majority of anticancer drugs. Therefore, the regulation of kinase-dependent proliferation pathways by GSTs is more significant than their catalytic properties alone [31].

GSTs undergo protein:protein interactions with critical kinases during regulation of cellular signaling involved in controlling stress response, apoptosis and proliferation. It negatively regulates signaling pathways through sequestration of signaling kinases.

GSTP has been characterized as a Jun kinase (JNK) inhibitor and GSTM1 binds to and inhibits the activity of ASK1 [32,33]. JNK has been implicated in pro-apoptotic signaling and ASK1 is an MAP kinase kinase. The mechanism of action involves activation of JNK, initiated by the phosphorylation of $\mathrm{c}$-Jun which in turn results in subsequent activation of downstream effectors. During non-stressed condition, there is low JNK1 catalytic activity due to its sequestration within the protein complex including at least GSTP and JNK [34]. However, under conditions of oxidative or chemical stress, a dissociation of the GSTP:JNK complex occurs releasing GSTP for oligomerization and JNK, allowing it for the subsequent commencement of apoptosis (Figure 2) [32,35]. The high levels of 
GSTP in many tumors may be a consequence of an acquired dependence on the protein. Many kinase pathways are dysregulated during proliferation, and subsequently tumor cells try to enhance GSTP expression in compensation to control kinase activity.

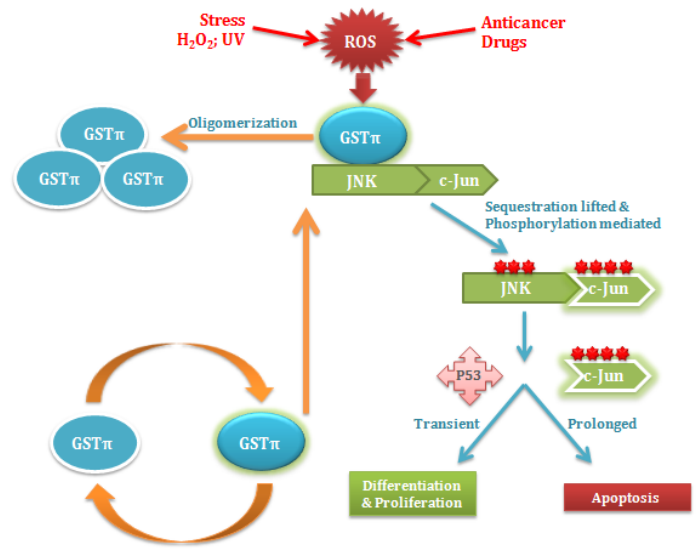

Figure 2: Role of GSTS in regulation of cellular signaling via kinases GSTP mediated activation of JNK.

Likewise, mechanism of GSTM1:ASK is similar to the one proposed for GSTP:JNK. ASK1 activates the $J N K$ and p38 pathways leading to cytokine and stress-induced apoptosis [36]. Under normal conditions, ASK1 exhibits low activity as it is sequestered by GSTM1 forming GSTM1:ASK1 complex, which is dissociated under stressful conditions leading to the release and activation of $A S K 1$ [37,38]. In oxidative stress or heat shock, GSTM1 oligomerizes and releases ASK1 which subsequently induces apoptosis [37]. Thus an altered expression of GSTM1 is found to be associated with impaired clinical response to therapy in a variety of tumor types.

Moreover GSTP has also been shown to play a necessary role in the glutathionylation of 1-cys peroxiredoxin (1-cysPrx). Oxidation of the catalytic cysteine of 1-cysPrx has been associated with its loss of peroxidase activity. The heterodimerization of 1-cysPrx with GSTP mediates the glutathionylation of the previously oxidized cysteine thus restoring its peroxidase activity [39]. Also the findings by Townsend et al. [40] suggest that GSTP may play a direct role in control of posttranslational glutathionylation reactions.

\section{Intonation of Signaling Pathways by GSTs}

GSTs antagonize expression of genes trans-activated by the peroxisome proliferator-activated receptor $\gamma(\operatorname{PPAR} \gamma)$ and nuclear factor-erythroid 2 p45-related factor 2 (Nrf2) in consequence to GSH conjugation of the signaling molecules 15-deoxy-_12,14-prostaglandin J2 (15d-PGJ2) and 4-hydroxynonenal substrates and GST may enhance gene expression driven by nuclear factor- $\kappa \mathrm{B}(\mathrm{NF}-\kappa \mathrm{B})$ through metabolism of $15 d-P G J 2$. 15d-PGJ2, a downstream metabolite of $P G D 2$, synthesis and breakdown is regulated by GSTs mainly as compared to other transferases. 15d-PGJ2 serves as an activating ligand for the peroxisome proliferator-activated receptor $\gamma$ (PPAR $\gamma)$ and is a critical regulator of adipocyte differentiation and also represents the molecular target of the thiazolidinedione class of insulin sensitizing drugs. GST over-expression reduces the transactivation of gene expression by $15 d-P G J 2$ mediated by PPAR $\gamma$ through conjugation of the prostanoid with GSH [41].

$15 d-P J 2$ can stimulate Nrf2-mediated induction of gene expression through the antioxidant response element (ARE) via mechanism whereby GSH conjugation of 15d-PGJ2 eradicates its ability to modify cytoskeleton-associated protein Keap1 (Kelchlike ECH-associated protein 1) [42,43]. 15d-PGJ2 modifies cysteine residues in the Keap1 rendering itunable to target $\mathrm{Nrf} 2$ for proteasomal degradation $[44,45]$. Similarly $15 \mathrm{~d}-\mathrm{PGJ} 2$ tends to inactivate the $\beta$ subunit of the inhibitor of $\kappa \mathrm{B}$ kinase (IKK $\beta)$ and inhibit NF- $\kappa \mathrm{B}$-dependent gene expression [46]. Thus the scope to which GST-catalyzed synthesis and/or metabolism of $15 d-P G J 2$ intrudes on these signaling pathways demands more research in this area (Figure 3).

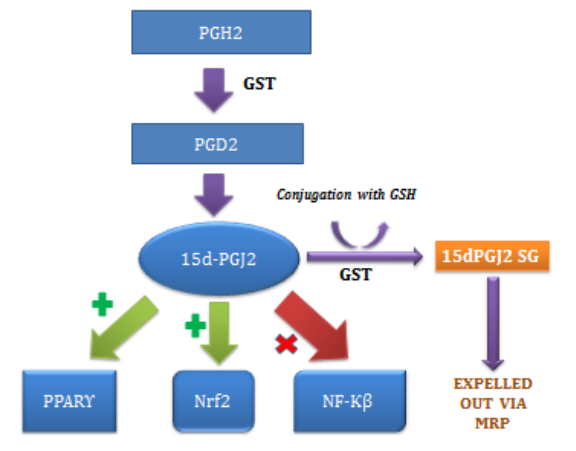

Figure 3: Attenuation of $15 d-P J 2$ signaling by GST.

Further the endogenous lipid peroxidation product 4hydroxynonenal (4-HNE) is believed to act as an intracellular signaling molecule that stimulates several components in signal transduction pathways, such as JNK, p38, and protein kinase C, as well as increases p53 protein and promotes apoptosis [47-49]. Its conjugation with GSH will influence a number of signal transduction pathways and modulates the activity of transcription factors, including NF- $\kappa \mathrm{B}, \mathrm{c}-\mathrm{Jun}$, and Nrf2. Like 15d-PGJ2, it can stimulate gene expression through the ARE [50] and also prevents activation of NF- $\kappa B$ by inhibiting I $\kappa$ phosphorylation. Collectively with $15 \mathrm{~d}-\mathrm{PGJ} 2$, it is plausible that Nrf2 mediates induction of ARE-driven genes by 4-HNE [2]. Reportedly, it modulates several cell-surface receptors; activate epithelial growth factor receptor and platelet-derived growth factor- $\beta$ receptor, and upregulate transforming growth factor receptor $\beta 1$.

\section{Polymorphism of GSTS}

A number of polymorphisms have been identified within each class of GSTs (Table 3). The M and T class of GST have a null phenotype $\left(G S T M^{\star} O\right.$ and $G S T T^{\star} 0$ ) whereby individuals do not express catalytically active protein.

\begin{tabular}{|l|l|l|l|l|}
\hline class & gene & allele & $\begin{array}{l}\text { gene/nucleotide } \\
\text { change }\end{array}$ & $\begin{array}{l}\text { amino acid/ } \\
\text { protein affect }\end{array}$ \\
\hline \multirow{2}{*}{ alpha } & \multirow{2}{*}{ gsta2 } & gsta2*a & $c 335, a 629$ & Thr112,Glu210 \\
\cline { 3 - 5 } & & gsta2* $B$ & $g 335, c 629$ & Ser112,Ala210 \\
\hline
\end{tabular}


Page 5 of 9

\begin{tabular}{|c|c|c|c|c|}
\hline & gstm1 & gstm1*a & $g 519$ & Lys 173 \\
\hline & & gstm $1 * b$ & c519 & Asn173 \\
\hline & & gstm $1 * 0$ & gene deletion & No Protein \\
\hline & & gstm $1 * 1 \times 2$ & Gene duplication & Overexpression \\
\hline \multicolumn{5}{|l|}{$\mathrm{mu}$} \\
\hline & \multirow[t]{2}{*}{ gstm3 } & gstm3*a & Wild type & Wild type \\
\hline & & gstm3*b & $\begin{array}{l}3 b p \text { deletion in } \\
\text { intron } 6\end{array}$ & $\begin{array}{l}\text { Primary structure } \\
\text { intact }\end{array}$ \\
\hline & & & & Wild type \\
\hline & & gstm $4^{*} a$ & Wild type & Unchanged \\
\hline & gstm4 & gstm $4 * b$ & intron change & \\
\hline & & gstp $1 * a$ & A313,C341,C555 & $\begin{array}{l}\text { Ile105,Ala114,Ser1 } \\
85\end{array}$ \\
\hline & gstp1 & gstp $1 * b$ & G313,C341,T555 & $\begin{array}{l}\text { Val105,Ala114,Ser } \\
185\end{array}$ \\
\hline \multirow[t]{3}{*}{ pi } & & $g s t p 1{ }^{*} c$ & G313,T341,T555 & $\begin{array}{l}\text { Val105,Val114,Ser } \\
185\end{array}$ \\
\hline & & gstp $1^{*} d$ & A313,Т341 & Ile105,Val114 \\
\hline & gstt1 & gstt ${ }^{*} a$ & Unique Gene & Unique Protein \\
\hline \multirow[t]{4}{*}{ theta } & & gstt ${ }^{*} \mathrm{O}$ & Gene Deletion & No Protein \\
\hline & gstt2 & gstt ${ }^{*} a$ & A415 & Met139 \\
\hline & & gstt2*b & G415 & Ile139 \\
\hline & & $g s t z 1^{* a} a$ & $A 94 ; A 124 ; C 245$ & Lys32;Arg42;Thr82 \\
\hline \multirow[t]{5}{*}{ zeta } & gstz1 & $g s t z 1^{*} b$ & A94;G124;C245 & Lys32;Gly42;Thr82 \\
\hline & & GSTz1 ${ }^{*} \mathrm{C}$ & G94;G124;C245 & Glu32;Gly42;Thr82 \\
\hline & & $g s t z 1^{*} d$ & G94;G124;T245 & $\begin{array}{l}\text { Glu32;Gly42;Met8 } \\
2\end{array}$ \\
\hline & \multirow{2}{*}{ MGST1 } & $M G S T 1^{*} A$ & T598(noncoding3') & wild type \\
\hline & & $m g s t 1^{*} b$ & g598(noncoding3') & unchanged \\
\hline & & $\operatorname{ltc} 4 s^{*} a$ & a-444(promoter) & \multirow{2}{*}{ Wild type } \\
\hline \multirow{3}{*}{$\begin{array}{l}\text { MAPE } \\
\text { G }\end{array}$} & $1 \mathrm{tc} 4 \mathrm{~s}$ & Itc $4 s^{*} b$ & c-444(promoter) & \\
\hline & \multirow{2}{*}{ flap } & flap*a & No Hindiii site & wild type \\
\hline & & flap*b & $\begin{array}{l}t-c \text { forming Hindiii } \\
\text { site }\end{array}$ & Unchanged \\
\hline
\end{tabular}

Table 3: Polymorphism of different GST genes.

The $G S T M 1^{*} O$ allele is observed in approx. 40 to $60 \%$ of the Caucasian population [51] and is associated with an increased risk of lung, prostate, gastric and bladder cancer and is a risk factor for head and neck cancer $[52,53]$. The GSTT ${ }^{\star} 0$ phenotype varies between ethnic

groups and is found to be highest in Chinese (65\%) and lowest in Mexican American (9\%) populations [54]. The GSTT ${ }^{\star} 0$ phenotype is associated with an increased risk of tumors of the head and neck, oral cavity, pharynx, and larynx $[55,56]$.

The GSTM1 gene contains four alleles and has been the most widely studied. GSTM1 polymorphism M1*A 0.2 is associated with decreased risk of bladder and breast cancer in Caucasians. M1*B 0.2 with decreased risk of pituitary adenomas; $\mathrm{M}^{\star}{ }^{\star} 0.59$ has been shown to increase the risk of lung, colon, bladder, and post-menopausal breast cancer. $G S T M 1^{*} A$ has been associated with a decreased risk of bladder cancer and has an allele frequency of $20 \%$ [57].

It is estimated that $10-20 \%$ of the Caucasian population are carriers of the GSTP1 null genotype. GSTP1 gene polymorphism is most often a point mutation SNP (single nucleotide polymorphism) within exon 5 Ile105 Val. Thus, the results of mutation are GSTP1 genotypes Ile/Ile, Ile/Val and Val/Val. The exchange of isoleucine and valine in the amino acid chain results in decreased enzymatic activity of protein $[58,59]$.

Also polymorphisms at the GSTP1 locus result in four alleles, $G S T P 1^{*} A-D$, that differ structurally and functionally. The promoter region contains a TATA box, two SP1 sites, an insulin response element and an anti-oxidant response element within an AP1 site [60]. $G S T P 1^{*} A$ plays a role in the acquisition of resistance to cisplatin (CDDP) by enhancing the capacity of the cell to form platinum-GSH conjugates/CDDP-GSH adducts [61]. GSTP1 ${ }^{*} B$ is an allele in which a single nucleotide $(A \rightarrow G)$ substitution at position 313 substantially diminishes catalytic activity [62]. Homozygosity for $G S T P 1^{\star} B$ is favorable in the treatment of cancer patients because they have a diminished capacity to detoxify platinum based anticancer agents [63]. $G S T P 1^{*} C$ is an allelic variant that is more predominant in malignant glioma cells and differs from other GSTP1 variants by two transitions resulting in Ile104Val and Ala113Val [60]. No major functional property has yet been assigned to this polymorphism.

Four $\left(G S T Z 1^{*} A-D\right)$ polymorphisms have been identified. As GSTZ1 ${ }^{*} A \quad$ (Lys32;Arg42;Thr82); GSTZ1*B (Lys32;Gly42;Thr82); GSTZ1 ${ }^{*} C$ (Glu32;Gly42;Thr82); GSTZ1 ${ }^{*} D$ (Glu32;Gly42;Met82). The isozyme $G S T Z 1^{*} A$ has the highest catalytic activity in contrast to GSTZ1 ${ }^{\star} \mathrm{D}$ which has been shown to be associated with inborn errors in tyrosine metabolism, along with mutations in other enzymes. Rodent models deficient for GSTZ1 provide insight into its role in metabolic deficiencies [31].

\section{GSTs and colorectal cancer}

A vast literature is currently available regarding the single nucleotide polymorphisms (SNPs) of GST genes as risk modulating factors in different cancers including gastrointestinal cancer. These SNPs affect the functioning of GST enzymes at the gene level as well as protein level, thereby influencing the detoxification process of carcinogens, and consequently, the level of DNA damage; thus it may have an indirect effect on the risk of development of cancer [64]. Multiple studies have been carried out from time to time to assess the impact of GST gene polymorphisms in colorectal cancer development and progression (Table 4). The results of these studies are inconsistent: some suggesting no association, some a low risk whereas others show increased risk and are summarized as follows:

\begin{tabular}{|l|l|l|l|}
\hline STUDY & $\begin{array}{l}\text { SAMPLE } \\
\text { POPULATION }\end{array}$ & RISK & $\begin{array}{l}\text { CONCOMITANC } \\
\text { E }\end{array}$ \\
\hline
\end{tabular}




\begin{tabular}{|c|c|c|c|}
\hline Loktionov et al. [65] & $\begin{array}{l}206 \text { cases; } 355 \\
\text { controls }\end{array}$ & $\begin{array}{l}\text { GSTM1 and } \\
\text { GSTM3 } \\
\text { polymorphism is } \\
\text { associated with } \\
\text { high CRC risk }\end{array}$ & \\
\hline \multirow{2}{*}{ Hlavata et al. [68] } & \multirow{2}{*}{$\begin{array}{l}\text { Czech } \\
\text { population(495) }\end{array}$} & $\begin{array}{ll}\text { Moderate } & \\
\text { increase } & \text { in risk } \\
\text { by } & \text { GSTM1 } \\
\text { deletion } & \end{array}$ & \multirow{2}{*}{\begin{tabular}{l}
\multicolumn{3}{l}{ Simultaneous } \\
deletion of the \\
GSTM1 and \\
GSTT1 genes \\
causes \\
significantly \\
higher risk.
\end{tabular}} \\
\hline & & $\begin{array}{l}\text { No risk by } \\
\text { GSTP1 gene } \\
\text { polymorphism }\end{array}$ & \\
\hline $\begin{array}{l}\text { Economopoulos et } \\
\text { al. [70] }\end{array}$ & $\begin{array}{l}\text { Caucasian } \\
\text { population }\end{array}$ & $\begin{array}{lr}\text { GSTM1 as } & \text { well } \\
\text { as GSTT1 } & \text { null } \\
\text { carriers } & \text { exhibit } \\
\text { increased } & \text { CRC } \\
\text { risk. } & \end{array}$ & \\
\hline $\begin{array}{l}\text { Aghajany-Nasab et } \\
\text { al. [69] }\end{array}$ & $\begin{array}{l}\text { Iran ( } 140 \text { cases; } \\
90 \text { controls) }\end{array}$ & $\begin{array}{l}\text { GSTM1 null } \\
\text { predisposes to } \\
\text { the development } \\
\text { of CRC in } \\
\text { individuals aged } \\
\text { over } 60\end{array}$ & \\
\hline \multirow{2}{*}{ Wang et al. [66] } & \multirow{2}{*}{$\begin{array}{l}\text { Indian Hindus } \\
(300)\end{array}$} & $\begin{array}{l}\text { GSTM1 null } \\
\text { increased risk of } \\
\text { rectal cancer }\end{array}$ & \multirow{2}{*}{$\begin{array}{l}\text { Predisposing to } \\
\text { the development } \\
\text { of CRC }\end{array}$} \\
\hline & & $\begin{array}{l}\text { GSTT1 null } \\
\text { increased risk of } \\
\text { colon cancer }\end{array}$ & \\
\hline Darazy et al. [67] & $\begin{array}{l}\text { Lebanese } \\
\text { population }\end{array}$ & $\begin{array}{l}\text { GSTM1 null } \\
\text { genotype } \\
\text { increased risk of } \\
\text { CRC }\end{array}$ & \\
\hline Hezova et al. [59] & $\begin{array}{l}\text { Czech } \\
\text { population(197 } \\
\text { cases; } \quad 218 \\
\text { controls) }\end{array}$ & $\begin{array}{lr}\text { No } & \text { significant } \\
\text { risk } & \text { of } \\
\text { development } & \text { of } \\
\text { CRC } & \text { by GSTM1 } \\
\text { and GSTT1. }\end{array}$ & \\
\hline $\begin{array}{l}\text { Khabaz MN et al. } \\
\text { [71] }\end{array}$ & Jordan & $\begin{array}{l}\text { GSTP1 lle } 105 \mathrm{Val} \\
\text { polymorphism } \\
\text { does not exert } \\
\text { any risk of CRC }\end{array}$ & \\
\hline Zhao et al. [72] & China & $\begin{array}{l}\text { GSTP1, GSTT1 } \\
\text { and GSTM1 } \\
\text { gene } \\
\text { polymorphisms } \\
\text { are } \\
\begin{array}{ll}\text { Colorectal } & \\
\text { Adenoma } & \text { risk } \\
\text { factors } & \end{array}\end{array}$ & No risk \\
\hline Kassab et al. [51] & $\begin{array}{lr}\text { Tunisian } & \\
\text { population } & (150 \\
\text { cases; } & 128 \\
\text { controls) } & \end{array}$ & $\begin{array}{l}\text { No significant } \\
\text { risk with } \text { GSTM1 } \\
\text { and GSTT1 null } \\
\text { genotypes but } \\
\text { significant risk for } \\
\text { CRC } \\
\text { GSTP1. with }\end{array}$ & \\
\hline Nissar et al. [73] & $\begin{array}{lr}\text { Kashmiri } & \\
\text { population } & (160 \\
\text { case; } & 200 \\
\text { controls }) & \end{array}$ & $\begin{array}{lr}\text { No significant } \\
\text { risk of CRC } \\
\text { GSTM1 } \\
\text { GSTT1 } & \text { and } \\
\text { genotypes } & \text { null }\end{array}$ & No risk \\
\hline
\end{tabular}

Table 4: GST polymorphisms and risk of colorectal cancer.
A study by Loktionov et al. [65] was conducted on 561 subjects (206 cases; 355 controls) and showed association of GSTM1 and GSTM3 polymorphisms with high risk of CRC development. Wang et al. [66] studied more than 300 patients belonging to the Indian Hindu population and proved that the GSTM1 null genotype is considerably related to an increased risk of rectal cancer and the GSTT1 null genotype to an elevated risk of colon cancer. Their study also recommended that the concomitance of polymorphism in three genes i.e, GSTM1, GSTT1 and GSTP1, may have an influencing role in the development of CRC.

Darazy et al. [67], suggested a significantly increased risk of colorectal cancer in individuals with the GSTM1 null genotype in the Lebanese population indicating similarity of results with the studies done on the Caucasian population. Hlavata et al. [68] also suggested an association of GSTM1 null genotype with a moderately increased risk of colorectal cancer development in the Czech population, whereas the simultaneous deletion of the both GSTM1 and GSTT1 genes causes a significantly higher risk of the development of CRC, in relation to the presence of both genes. Another study by Aghajany-Nasab et al. [69] conducted in Iran on 230 subjects (140 cases; 90 controls) indicated the GSTM1 null genotype predisposes to the development of CRC in individuals greater than 60 years of age. Economopoulos et al. [70] showed GSTM1 as well as GSTT1 null carriers' exhibit increased CRC risk in Caucasians.

However there are number of studies which show opposite results, like a study by Hezova et al. [59] on Czech population shows no significant risk of development of CRC by GSTM1 and GSTT1 null genotypes. Another study from Jordan by Khabaz MN [71] revealed no statistically significant differences between GSTP1 genotypes and CRC risk.

Further it was observed that GSTP1, GSTT1 and GSTM1 gene polymorphisms are not colorectal adenoma risk factors in a Chinese meta- analysis study conducted by Zhao et al. [72] and Kassab et al. [51] also showed that there is no significant risk with GSTM1 and GSTT1 null genotypes but a significant risk for CRC with GSTP1 in the Tunisian population.

In our own study in Kashmiri population, we found a nonsignificant $(\mathrm{p}>0.05)$ association of GSTMInull and GSTTInull polymorphism with the CRC. However the individuals with doublenull genotype (GSTM1-/GSTT1-) were found to have 3.5 fold increased risk for development of CRC [73].

The dissatisfaction of such studies in establishing some positive associations between GST polymorphisms and colorectal cancer does not inevitably eliminate the possibility of other variants or combinations of alleles on multiple positions in the same genes as relevant to the cancer. Thus such inconsistent results reflect the complexity in the role of GSTs and refer to the fact that the metabolic pathways involved in the carcinogen metabolism are complex and facilitated by the actions of multiple genes. Despite all these observations, there is still no consensus regarding the significance of GST gene polymorphism in the development of colorectal cancer risk.

\section{GSTs, colorectal cancer and diet}

The variations in the metabolism of genotoxic compound by xenobiotic metabolising enzyme (XME) genes result in the genetic predisposition to cancer. Although the risk is fairly modest, but the impact of environmental exposure and/or diet may be dangerous $[74,75]$. Both nutrients and xenobiotics tend to modulate the inducible 
Page 7 of 9

sequences in promoter regions, called responsive elements thereby affectingthe gene expression. Conversely, a genetic polymorphism in XME governs the effects of specific nutrients by alterations in their biotransformation $[76,77]$ henceforth; the link between diet and genes seems to be bidirectional. These 'antioxidant responsive element' (ARE) found in the promoter region of numerous XME are prompted by both mono-functional inducers like transcription factor NF-E2related factor-2 and Maf proteins, as well as bi-functional inducers like phytochemicals. These ARE's then activate the gene expression and hence are crucial in cancer protection functionality [78,79]. The individual genotypes of common polymorphisms modify the bioavailability, metabolism, affinity and activity of several dietary constituents with potential carcinogenic activity (e.g. heterocyclic amine (HCA), polycyclic aromatic hydrocarbon (PAH), aflatoxin).The process of activation by phase I enzymes and detoxification by phase II enzymes includes environmental, dietary xenobiotics as well as protective components of the diet [80], which can influence the modulation of biotransformation enzymes [81]. Evidently the diet and genetic polymorphism of detoxifying enzymes is associated with PAHDNA adduct formation and cancer risk. Several studies on genenutrient interactions show an association between nutrient level and DNA adduct formation and GST genetic polymorphismin CRC.

Further an efficient review including 2,500 studies proposed a relationship between both GSTT1 and GSTM1 gene polymorphism and dietary factors in the risk of development of CRC; however, it may require validation by some other independent potential studies [82]. Hence there is no consensus vis-à-vis GST gene polymorphism and the development of CRC. The results in various populations do not overlap, and sometimes are even contradictory. This may possibly be due to the fact that such studies are specific to individual genes of the GST family in the risk of developing CRC and do not consider the effect of other environmental factors.

\section{Conclusion}

In conclusion, we can suggest that the field of xenobiotic metabolism and the genes associated has drawn a lot of audience to research upon the effect of various gene SNPs on the assembly and functioning of the glutathione dependent enzymes vis-a-vis the risk of CRC. However, due to huge genetic variance among various populations and the different set of environmental exposures, the results of various studies vary substantially. Nevertheless, all studies have shed a light upon the association of GST gene polymorphisms and the development of CRC. But, future epidemiological studies should focus on continuing to clarify the role of gene-nutrient interactions in the etiology of CRC.

Moreover, independent population-based studies assessing the influence of GST family gene variations and environmental factors, such as diet and lifestyle, on the risk of modulating the CRC carcinogenesis is the need of an hour. So keeping this in mind, epidemiological studies focusing on the interactions between nutrients and genes have great potential not only for understanding the relevant underlining mechanisms of carcinogenesis but also in identifying the susceptible populations/individuals as well. This will further allow the translation of these findings to clinical practice for better management of the disease. Therefore, further large scale studies on this gene family are suggested so as to help in the development of effective diagnostic and prognostic tools for the management and treatment of CRC.

\section{References}

1. Strange RC (2000) Glutathione S-transferase: genetics and role in toxicology. Toxicol Lett 112: 357-363.

2. Hayes JD (2005) Glutathione transferases. Annu Rev Pharmacol Toxicol 45: 51-88.

3. Senhaji N (2015) Genetic Polymorphisms of Multidrug Resistance Gene-1 (MDR1/ABCB1) and Glutathione S-Transferase Gene and the Risk of Inflammatory Bowel Disease among Moroccan Patients. Mediators of Inflammation 24: 8060.

4. Nebert DW, Vasiliou V (2004) Analysis of the glutathione S-transferase (GST) gene family. Human Genomics 1: 460-464.

5. Hayes JD, Strange RC (2000) Glutathione S-transferase polymorphisms and their biological consequences. Pharmacology 61: 154-166.

6. Coleman JOD (1997) Detoxification of xenobiotics by plants: chemical modification and vacuolar compartmentation. Trends Plant Sci 2: 144-151.

7. Board PG (2000) Identification, characterization, and crystal structure of the Omega class glutathione transferases. J Biol Chem 275: 24798-24806.

8. Axarli IA (2004) Characterization of the ligandin site of maize glutathione S-transferase I. Biochem J 382: 885-893.

9. Ji XH (1995) 3-Dimensional structure, catalytic properties, and evolution of a sigma-class glutathione transferase from squid, a progenitor of the lens S-crystallins of cephalopods. Biochemistry 34: 5317-5328.

10. Frova C (2006) Glutathione transferases in the genomics era: new insights and perspectives. Biomol Eng 23: 149-169.

11. Haimeur A (2004) The MRP-related and BCRP/ABCG2 multidrug resistance proteins: biology, substrate specificity and regulation. Curr Drug Metab 5: 21-53.

12. Paumi CM (2001) Role of multidrug resistance protein $1(M R P 1)$ and glutathione S-transferase A1-1 in alkylating agent resistance. Kinetics of glutathione conjugate formation and efflux govern differential cellular sensitivity to chlorambucil versus melphalan toxicity. J Biol Chem 276: $7952-7956$.

13. Morrow CS (2000) Role of multidrug-resistance protein 2 in glutathione S-transferase P1-1-mediated resistance to 4-nitroquinoline1-oxide toxicities in HepG2 cells. Mol Carcinog 29: 170-178.

14. Awasthi S (2002) RLIP76, a novel transporter catalysingATPdependent efflux of xenobiotics. Drug Metab Dispos 30: 1300-1310.

15. Hamilton DS (2003) Mechanism of the glutathione transferase catalyzed conversion of antitumor 2-crotonyloxymethyl-2-cycloalkenones to GSH adducts. Am Chem Soc 125: 15049-15058.

16. Abel EL (2004) Biotransformation of methyl parathion by glutathione Stransferases. Toxicol Sci 79: 224-232.

17. Abel EL (2004) Characterization of atrazine biotransformation by human glutathione S-transferases. Toxicol Sci 80: 230-236.

18. Li J (2005) Thioredoxin-like domain of human $\mathrm{k}$ class glutathione transferase reveals sequence homology and structure similarity to the $y$ class enzyme. Protein Science 14: 2361-2369.

19. Yang Y (2002) Role of a class glutathione S-transferases as antioxidant enzymes in rodent tissues. Toxicol Appl Pharmacol 182: 105-115.

20. Prabhu KS (2004) Characterization of a class alpha glutathione Stransferase with glutathione peroxidase activity in human liver microsomes. Arch Biochem Biophys 424: 72-80.

21. Hamdy SI (2002) Genotype and allele frequencies of TPMT, NAT2, GST, SULT1A1 and MDR-1 in the Egyptian population.Br J ClinPharmacol 55: 560-569.

22. Liang $\mathrm{T}$ (2004) Glutathione S-Transferase 8-8 Expression Is Lower in Alcohol Preferring Than in Alcohol-Nonpreferring Rats. Alcohol ClinExp Res 28: 1622-1628.

23. Manevich Y (2004) Activation of the antioxidant enzyme 1-CYS peroxiredoxin requires glutathionylation mediated by heterodimerization with pGST. Proc Natl Acad Sci 101: 3780-3785. 
24. Guengerich FP (2003) Analysis of the kinetic mechanism of haloalkane conjugation by mammalian Theta-class glutathione transferases. Chem Res Toxicol 16: 1493-1499.

25. Wheeler JB (2001) Conjugation of haloalkanes by bacterial and mammalian glutathione transferases: mono- and dihalomethanes. Chem Res Toxicol 14: 1118-1127.

26. Xu K, Thornalley PJ (2001) Involvement of glutathione metabolism in the cytotoxicity of the phenethylisothiocyanate and its cysteine conjugate to human leukaemia cells in vitro. Biochem Pharmacol 61: 165-177.

27. Han X (2011) Metabolism of 1,2,3,3,3-Pentafluoropropene in Male and Female Mouse, Rat, Dog, and Human Liver Microsomes and Cytosol and Male Rat Hepatocytes via Oxidative Dehalogenation and Glutathione SConjugation Pathways. Drug MetabDispos 39: 1288-1293.

28. Lyttle $\mathrm{MH}$ (1994) Glutathione S-transferase activates novel alkylating agents. J Med Chem 37: 1501-1507.

29. Rosen LS (2003) Phase I study of TLK286 (glutathione S-transferase P1-1 activated glutathione analogue) in advanced refractory solid malignancies. Clin Cancer Res 9: 1628-1638.

30. Findlay VJ (2004) Tumor cell responses to a novel glutathione Stransferase-activated nitric oxide-releasing prodrug. Mol Pharmacol 65 1070-1079.

31. McIlwain CC (2006) Glutathione S-transferase polymorphisms: cancer incidence and therapy. Oncogene 25: 1639-1648.

32. Townsend DM, Tew KD (2003) The role of glutathione-S-transferase in anti-cancer drug resistance. Oncogene 22: 7369-7375.

33. Cho SG (2001) Glutathione S-transferase mu modulates the stressactivated signals by suppressing apoptosis signal-regulating kinase 1 . J BiolChem 276: 12749-12755.

34. Adler V (1999) Regulation of JNK signaling by GSTp. EMBO J 18: 13211334.

35. Davis W Jr (2001) Cellular thiols and reactive oxygen wspecies in druginduced apoptosis. J Pharmacol ExpTher 296: 1-6.

36. Bhattacharya P (2013) Glutathione S-transferase class mu regulation of apoptosis signal-related kinase 1 protein during VCD-induced ovotoxicity in neonatal rat ovaries. Toxicol Appl Pharmacol 267: 49-55.

37. Dorion S (2000) Activation of the p38 signaling pathway by heat shock involves the dissociation of glutathione S-transferase Mu from Ask 1. J Biol Chem 277: 30792-30797.

38. Sekinel Y, Hatanaka R, Watanabe T, Sono N, Lemura S, et al. (2012) The Kelch Repeat Protein KLHDC10 Regulates Oxidative Stress-Induced ASK1 Activation by Suppressing PP5. Mol Cell 48: 692-704.

39. Manevich Y, Fisher AB (2005) Peroxiredoxin 6, a 1-Cys peroxiredoxin functions in antioxidant defense and lung phospholipid metabolism. Free Radic Biol Med 38: 1422-1432.

40. Townsend DM (2006) A glutathione S-transferase pi-activated prodrug causes kinase activation concurrent with S-glutathionylation of proteins. Mol Pharmacol 69: 501-508.

41. Paumi CM (2004) Glutathione Stransferases (GSTs) inhibit transcriptional activation by the peroxisomal proliferator- activated receptor $\gamma(\operatorname{PPAR} \gamma)$ ligand, 15-deoxy-12,14-prostaglandin J2(15-dPGJ2). Biochemistry 43: 2345-2352.

42. Jowsey IR (2003) Expression of the murine glutathione S-transferase a3 (GSTA3) subunit is markedly induced during adipocyte differentiation: activation of the GSTA3 gene promoter by the proadipogenic eicosanoid 15-deoxy-12,14- prostaglandin J2. Biochem.Biophys. Res Commun 312: $1226-1235$.

43. Itoh K (2004) Transcription factor Nrf2 regulates inflammation by mediating the effect of 15-deoxy-12,14-prostaglandin J2. Mol Cell Biol 24 36- 45 .

44. McMahon M (2003) Keap1-dependent proteasomal degradation of transcription factor $\mathrm{Nrf} 2$ contributes to the negative regulation of antioxidant response element-driven gene expression. J Biol Chem 278: $21592-21600$
45. Wakabayashi N (2004) Protection against electrophile and oxidant stress by induction of the phase 2 response: fate of cysteines of the Keap 1 sensor modified by inducers. Proc Natl Acad Sci 101: 2040-2045.

46. Rossi A (2000) Anti-inflammatory cyclopentenone prostaglandins are direct inhibitors of IкB kinase. Nature 403: 103-108.

47. Uchida K (2003) 4-Hydroxy-2-nonenal: a product and mediator of oxidative stress. Prog Lipid Res 42: 318-343.

48. Echtay K (2003) A signaling role for 4-hydroxy-2-nonenal in regulation of mitochondrial uncoupling. EMBO J 22: 4103-4010.

49. Awasthi YC (2003) Role of 4-hydroxynonenal in stress-mediated apoptosis signalling. Mol Aspects Med. 24: 219-230.

50. Tjalkens RB (1999) $\alpha, \beta$-Unsaturated aldehydes mediate inducible expression of glutathione S-transferase in hepatoma cells through activation of the antioxidant response element (ARE). Adv Exp Med Biol 463: 123-131.

51. Kassab A (2014) Polymorphisms of glutathione-S-transferases M1, T1, P1 and susceptibility to colorectal cancer in a sample of the Tunisian population. Med Oncol 31: 760.

52. Di Pietro G (2010) Glutathione S-transferases: an overview in cancer research. Expert Opin Drug Metab Toxicol 6: 153-170.

53. Hashibe M (2003) Meta and pooled analyses of GSTM1, GSTT1, GSTP1, and CYP1A1 genotypes and risk of head and neck cancer. Cancer Epidemiol Biomarkers Prev. 12: 1509-1517.

54. Nelson HH (1995) Ethnic differences in the prevalence of the homozygous deleted genotype of glutathione S-transferase theta. Carcinogenesis 16: 1243-1245.

55. Strange RC, Fryer AA (1999) The glutathione S-transferases: influence of polymorphism on cancer susceptibility. IARC Sci Publ 19: 231-249.

56. Chenevix-Trench G (1995) Glutathione S-transferase M1 and T1 polymorphisms: susceptibility to colon cancer and age of onset. Carcinogenesis 16: 1655-1657.

57. Smith G (1995) Metabolic polymorphisms and cancer susceptibility. Cancer Surv 25: 27-65.

58. Wei B (2012) Association of GSTM1 null allele with prostate cancer risk: evidence from 36 case-control studies. PLoS One 10: e46982.

59. Hezova R (2012) Common polymorphisms in GSTM1, GSTT1, GSTP1, GSTA1 and susceptibility of colorectal cancer in the Central European population. Eur J Med Res 17: 17-22.

60. Lo HW, Ali-Osman F (1998) Structure of the human allelic glutathione Stransferase-pi gene variant, hGSTP1 C, cloned from a glioblastoma multiforme cell line. Chem Biol Interact 111: 91-102.

61. Goekkurt E (2006) Polymorphisms of glutathione S-transferases (GST) and thymidylate synthase (TS)-novel predictors for response and survival in gastric cancer patients. Br J Can 94: 281-286.

62. Sharma A (2014) Genetic polymorphism of glutathione S-transferase P1 (GSTP1) in Delhi population and comparison with other global populations. Meta Gene 2: 134-142.

63. Stoehlmacher J (2002) Association between glutathione S-transferase P1, T1, And M1 genetic polymorphism and survival of patients with metastatic colorectal cancer. J Natl Cancer Inst 94: 936-942.

64. Gong M (2012) Genetic polymorphism of GSTM1, GSTT1 and GSTP1 with prostate cancer risk: a meta-analysis of 57 studies. PLoS One 7: e50587.

65. Loktionov A (2001) Glutathione-S-transferase gene polymorphisms in colorectal cancer patients: interaction between GSTM1 and GSTM3 allele variants as a risk-modulating factor. Carcinogenesis 22: 1053-1060.

66. Wang J (2011) Genetic polymorphisms of glutathione S-transferase genes and susceptibility to colorectal cancer: a case-control study in an Indian population. Cancer Epidemiol 35: 66-72.

67. Darazy M (2011) CYP1A1, CYP2E1, and GSTM1 gene polymorphisms and susceptibility to colorectal and gastrin cancer among Lebanese. Genet Test Mol Biomarkers. 15: 423-429.

68. Hlavata I (2010) Association between exposure-relevant polymorphisms in CYP1B1, EPHX1, NQO1, GSTM1, GSTP1 and GSTT1 and risk of colorectal cancer in a Czech population. Oncol Rep 24: 1347-1353. 
Citation: Nissar S, Sameer AS, Rasool R, Chowdri NA, Rashid F (2017) Glutathione S Transferases: Biochemistry, Polymorphism and Role in Colorectal Carcinogenesis. J Carcinog Mutagen 8: 286. doi:10.4172/2157-2518.1000287

Page 9 of 9

69. Aghajany-Nasab M (2011) Glutathione S-transferase mu gene variants and colorectal cancer development-use of sequence-specific probes for an Iranian population. Asian Pac J Cancer Prev 12: 1511-1515.

70. Economopoulos KP, Sergentanis TN (2010) STM1, GSTT1, GSTP1, GSTA1 and colorectal cancer risk: a comprehensive meta-analysis. Eur J Cancer 46: 1617-1631.

71. Khabaz MN (2012) The GSTP1 Ile105Val polymorphism is not associated with susceptibility to colorectal cancer. Asian Pac J Cancer Prev 13: 2949-2953.

72. Zhao ZQ (2012) System review and meta-analysis of the relationships between five metabolic gene polymorphisms and colorectal adenoma risk. Tumor Biol 33: 523-535.

73. Nissar S, Sameer AS, Rasool R, Chowdri N, Rashid F (2017) Evaluation of deletion polymorphisms of Glutathione-S-Transferase (GST) genes and colorectal cancer risk in ethnic Kashmiri population: A case control study. Indian J Cancer 16: 2.

74. Torre LA (2015) Global Cancer Incidence and Mortality Rates and Trends-An Update. Cancer Epidemiol Biomarkers Prev 25: 16-27.

75. Reszka E, Wasowicz W (2001) Significance of genetic polymorphisms in glutathione S-transferase multigene family and lung cancer risk. Int J Occup Med Environm Health 14: 99-113.
76. Milner JA (2003) Incorporating basic nutrition science into health interventions for cancer prevention. J Nutr 133: 3820-3826.

77. Paoloni-Giacobino A (2003). Genetic and nutrition. Clin Nutr 22: 429_ 443.

78. Hayes JD, McMahon M (2001) Molecular basis for the contribution of the antioxidant responsive element to cancer chemoprevention. Cancer Lett 174: 103-113.

79. Talalay P, Fahey JW (2001) Phytochemicals from cruciferous plants protect against cancer by modulating carcinogen metabolism. J Nutr 131: 3027-3033.

80. Reszka E (2007) Antioxidant defense markers modulated by glutathione S-transferase genetic polymorphism: results of lung cancer case-control study. Genes Nutr 2: 287-294.

81. Wargovich MJ, Cunningham JE (2003) Diet, individual responsiveness and cancer prevention. J Nutr 133: 2400-2403.

82. Andersen V (2013) Systematic review: diet-gene interactions and the risk of colorectal cancer. Aliment Pharmacol Ther 37: 383-391. 